\title{
ASSISTÊNCIA TÉCNICA COMUNITÁRIA NA FORMAÇÃO DO PROFISSIONAL DE ENGENHARIA: PROJETO LUGAR DE LER
}

Débora Ferreira de Freitas - deborah.3m@hotmail.com

CEFET - MG campus Curvelo

Rua Joaquim Felício, 360 A, Centro

35790-171 - Curvelo - Minas Gerais

Eduardo André Avelino Júnior - eduardo01avelino@hotmail.com

CEFET - MG campus Curvelo

Rua Raymundo Mattoso, 900, Santa Rita

35790-000 - Curvelo - Minas Gerais

Hêmilly Liandra Saué Ribeiro - hemillyliandra@ gmail.com

CEFET - MG campus Curvelo

Rua Lino de Oliveira, 282 A, Centro

35790-010 - Curvelo - Minas Gerais

Julie Siqueira Gonçalves - juliegoncalvescvo@gmail.com

CEFET - MG campus Curvelo

Rua Costa Rica, 320, 1 Bela Vista

35790-000 - Curvelo - Minas Gerais

Luciana Patrícia Ferreira - lupiferreiracefetmg@ gmail.com

CEFET - MG campus Curvelo

Rua Raymundo Mattoso, 900, Santa Rita

35790-000 - Curvelo - Minas Gerais

Resumo: A pesquisa Retratos da Leitura no Brasil mostra que o país perdeu quase 90 milhões de leitores entre 2007 e 2011, a maioria crianças, com a intensificação da competição com outros meios de comunicação e a perda de qualidade na leitura. Em parceria com educadores interessados em desenvolver a capacidade de leitura espontânea surgiu o projeto Lugar de Ler, no qual alunos de engenharia do CEFET-MG Curvelo auxiliam uma escola da comunidade a desenvolver soluções para espaços econômicos e sustentáveis que dão suporte a prática de metodologias de aprendizagem. Nesse processo os alunos aplicam sua capacidade técnica instalada e as especialidades características dos profissionais em formação a serviço da comunidade, e permite a seus alunos vivenciar a função social da atividade profissional.

Palavras-chave: Assistência Técnica Comunitária. Leitura. Sustentabilidade.

\section{INTRODUÇÃO}

A pesquisa Retratos da Leitura no Brasil mostra que o país perdeu quase 90 milhões de leitores entre 2007 e 2011. Esse empobrecimento da leitura entre crianças foi mais sensível: de $8,5 \%$ para $6,4 \%$. Com a intensificação da competição com outros meios de comunicação e a perda de qualidade na leitura, se torna muito importante que as escolas sejam o foco 
motivador de leitura para uma sociedade desde a mais tenra idade. Desenvolver a capacidade de leitura espontânea em um estudante no ambiente escolar é um desejo comum nos educadores. Projetos educacionais, metodologias de ensino e outras intervenções que reforcem a criatividade e o desejo genuíno de leitura, oferecer as ferramentas básicas do desenvolvimento e difusão do conhecimento humano. Por outro lado Parâmetros Curriculares Nacionais - PCN que tratam dos Temas Transversais apontam que "São grandes os desafios a enfrentar quando se procura direcionar as ações para a melhoria das condições de vida no mundo. Um deles é relativo à mudança de atitudes na interação com o patrimônio básico para a vida humana: o meio ambiente" (PCN, 1998, p. 169).

A Escola Municipal Dr. Viriato Mascarenhas Gonzaga, localizada no Bela Vista, um bairro carente da cidade de Curvelo, e atende ao Centro de Educação Infantil - CAIC (Creche: 1 ano e 8 meses a 3 anos e Pré escola de 4 a 5 anos) e os anos iniciais do Ensino Fundamental, atende a 1500 crianças e conta com 150 funcionários. A escola já obteve reconhecimento de vários projetos realizados e foi premiada pela sua gestão escolar em 2015-2016, por sua atuação em múltiplos projetos culturais, educacionais e comunitários.

Figura 1 - CAIC Curvelo - Premiação de Gestão Escolar 2015 e Atividades Literárias
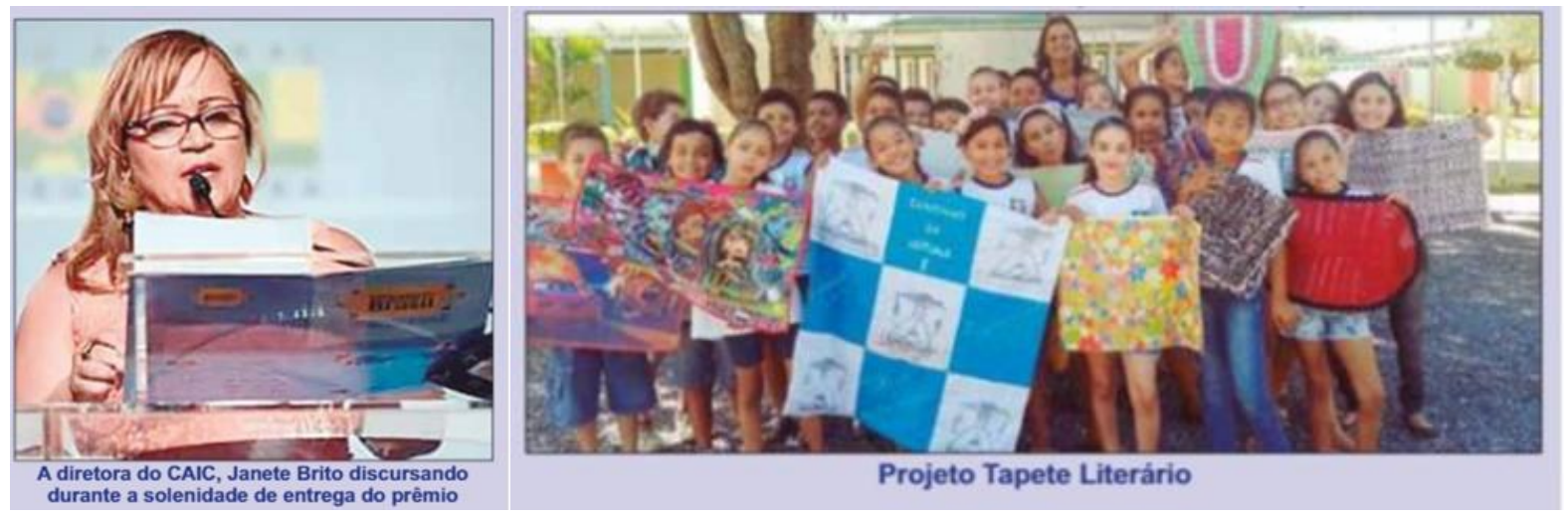

Fonte: Jornal Folha de Curvelo https://pt.calameo.com/books/0043045205f9ac2a76606

A presença de uma grande árvore próxima ao estacionamento do CAIC Curvelo foi a inspiração das diretoras para o projeto Árvores Literárias, que surgiu com a intenção de instigar o desejo pela leitura em espaços abertos. O CEFET-MG Curvelo, que já havia participado com o CAIC em projetos de inclusão digital, foi convidado para auxiliar com a requalificação do espaço e acompanhamento das obras.

A partir do projeto de extensão Lugar de Ler, ficou firmada a parceria entre CAIC e CEFET-MG Curvelo em 2018 com a proposta de um projeto dirigido às crianças de até 10 anos. As premissas eram que o espaço fosse multifuncional, sustentável e acolhedor, propício para as atividades relacionadas à leitura e contação de histórias e aberto à comunidade e que permita a identificação e a apropriação do espaço como patrimônio da comunidade.

A ação extensionista, principalmente nas unidades do CEFET-MG no interior cumpre uma função importante na difusão do conhecimento técnico e científico.

\section{OBJETIVO}

O objetivo principal do projeto é oferecer assistência técnica no sentido de preparar infraestruturas apropriadas para incentivar e ampliar o interesse na leitura entre alunos e população do município de Curvelo - MG. Os objetivos específicos são: Colocar em prática e a serviço da comunidade, a capacidade técnica instalada de alunos e servidores CEFET-MG 
Curvelo; Apoiar para o avanço da educação e da cultura na comunidade local; e permitir que os alunos do CEFET-MG tenham oportunidade de interagir com a comunidade em um projeto que permita perceber a responsabilidade social implícita na profissão.

\section{METODOLOGIA}

A metodologia se baseou nas seguintes etapas:

- Levantamento do espaço (e documentação) e do programa de necessidades;

- Pesquisa de soluções sustentáveis, econômicas e visando conforto e segurança dos usuários;

- Definição e desenho do projeto com requalificação dos espaços incluindo paisagismo;

- Apresentação aos gestores, à comunidade e à comunidade acadêmica;

- Avaliação do usuário: através de questionário em que os participantes poderão manifestar seu nível de satisfação com relação ao projeto, atendimento das expectativas e sugestões;

- Ajustes no projeto e reapresentação;

- Preparação de quantitativos e orçamento;

- Acompanhamento à execução de obras.

\section{DESENVOLVIMENTO}

Como o projeto ocuparia uma boa porção do quarteirão onde o CAIC Curvelo está localizado, o trabalho inicial da equipe foi fazer o levantamento de documentação. A documentação estava insuficiente e havia necessidade de medição. Com base nas fotos online foi possível recuperar os limites construídos. Na sequência passamos aos levantamentos de campo do estacionamento e locação de arborização do local.

Figura 2 - Localização e levantamento - documentação inicial

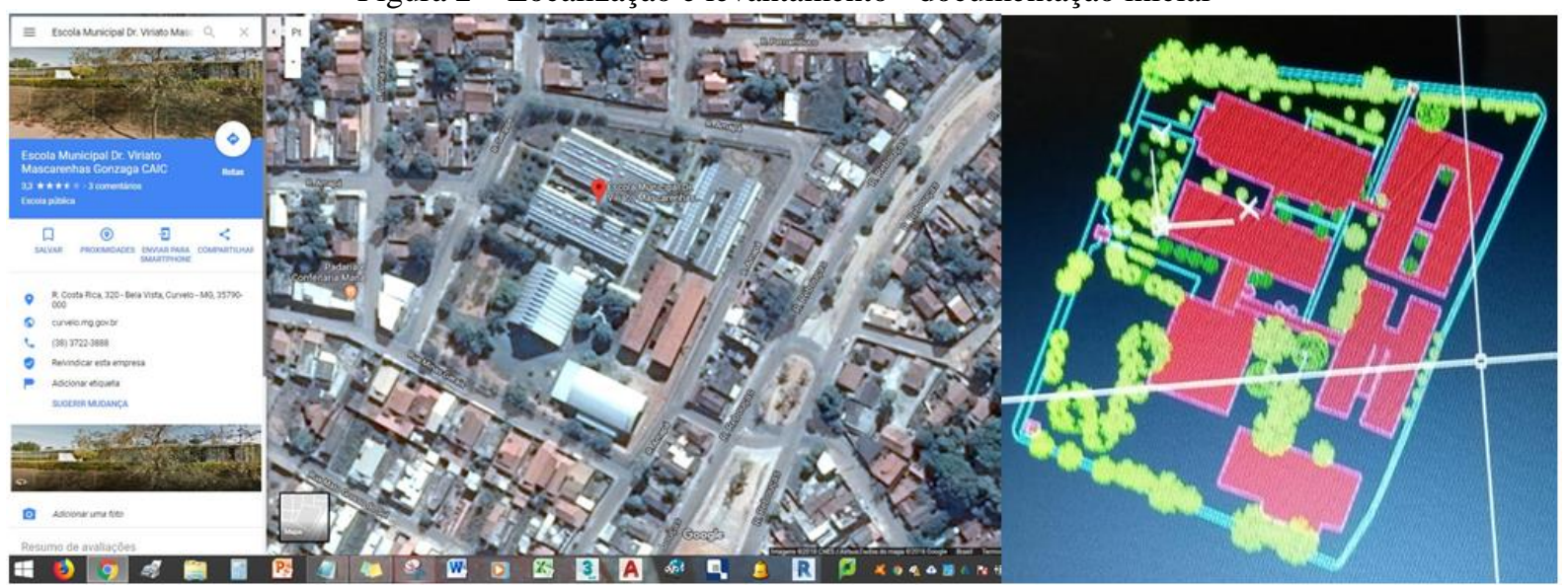

Fonte: Arquivo pessoal.

A especulação em torno de possibilidades econômicas, eco eficientes, estrutural e arquitetonicamente válidas passou pela análise de parâmetros e modelos que representassem adequadamente as necessidades do local. Utilizamos o procedimento de modelagem convencional para estudar e propor os parâmetros de estudo as envoltórias a ser utilizadas. Definiram-se os parâmetros de interesse e estabeleceram-se comparativos entre os resultados 
C COBENCE 2020

"Os desafios para formar hoje o engenheiro do amanhã"

do software para decidir a solução mais viável.

Figura 3 - Tabela da definição preliminar de parâmetros.

\begin{tabular}{|c|c|c|c|c|}
\hline Estrutura & Objetivo & Restrição & Material & Forma \\
\hline Símil Árvore & $\begin{array}{l}\text { Reduçẫo/ Otimização } \\
\text { de material }\end{array}$ & $\begin{array}{l}\text { Estabilidade } \\
\text { Economia } \\
\text { Segurança }\end{array}$ & $\begin{array}{l}\text { Fabric Formworq } \\
\text { - concreto }\end{array}$ & $\begin{array}{l}\text { Orgânica } \\
\text { (bifurcações) }\end{array}$ \\
\hline $\begin{array}{l}\text { Cobertura de } \\
\text { Arquibancada } \\
\text { (onfiteatro) }\end{array}$ & $\begin{array}{l}\text { Redução/Otimização } \\
\text { de apoios }\end{array}$ & $\begin{array}{l}\text { Estabilidade } \\
\text { Economia }\end{array}$ & $\begin{array}{l}\text { Madeira/metal + } \\
\text { tecido }\end{array}$ & $\begin{array}{l}\text { Circular em } \\
\text { espiral }\end{array}$ \\
\hline $\begin{array}{r}\text { Monte para } \\
\text { escalada }\end{array}$ & $\begin{array}{l}\text { Otimização de } \\
\text { material na estrutura }\end{array}$ & Estabilidade & Madeira/Solo & Montanha \\
\hline
\end{tabular}

Fonte: Arquivo pessoal.

A proposta partiu das premissas lúdicas de valorizar formas que semelhantes às formas naturais, gerar sombras que proporcionam conforto térmico e luminoso adequado e que fossem utilizados materiais sustentáveis. Uma importante limitação era o orçamento, logo os alunos lançaram mão de suas experiências com materiais alternativos eficientes e econômicos com os quais tinham contato ao longo de seus estudos de engenharia. Foram escolhidos materiais conhecidos, acessíveis ou abundantes como: o tijolo de solo-cimento, o bambu e a madeira de reflorestamento.

Figura 4 - Prospecção geometrias paramétricas e materiais.

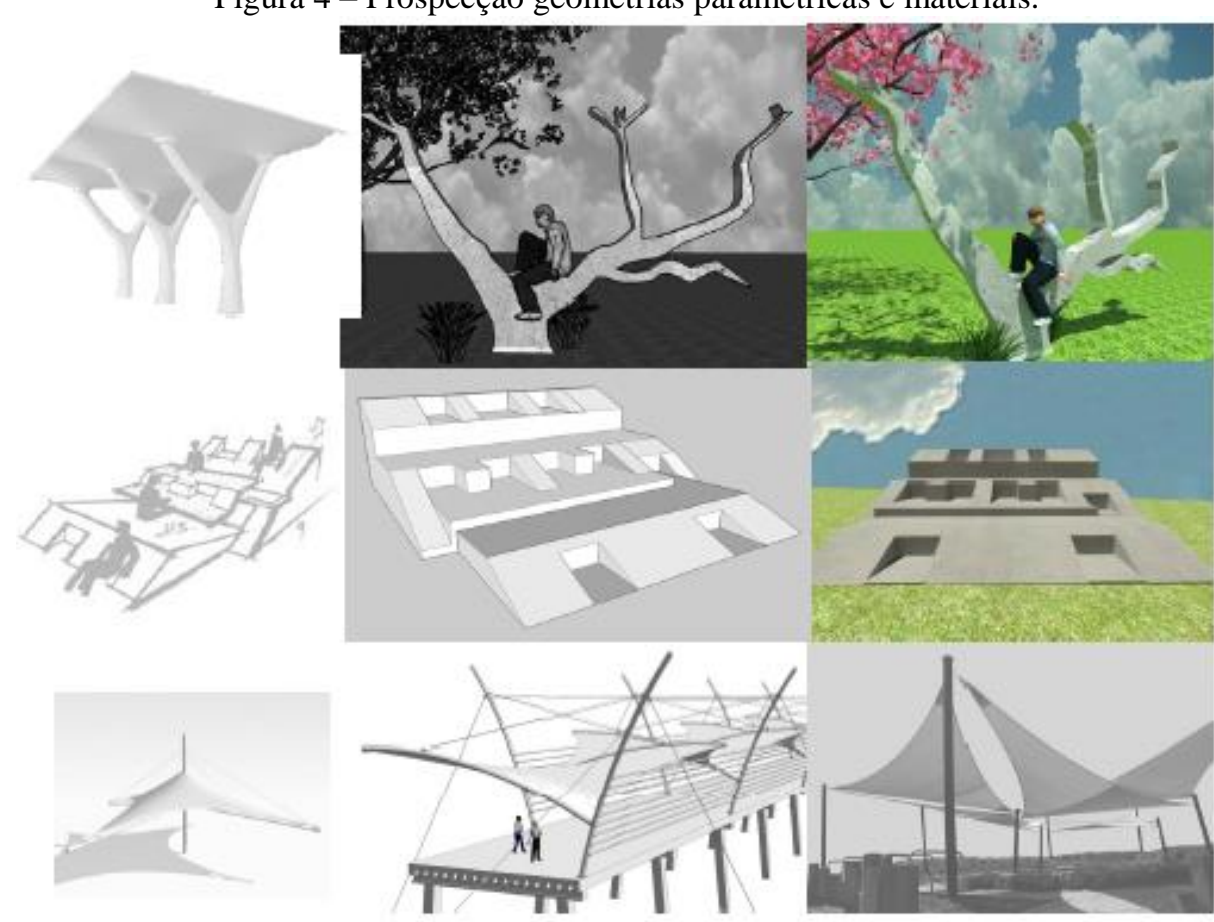

Fonte: Arquivo pessoal. 
Visando melhor aproveitar o espaço que já estava disponível, foi pensado na elaboração um lago artificial, que proporcionasse um ambiente tranquilo, para que as crianças pudessem se sentir bem ao realizar suas atividades, prezando sempre pelo equilíbrio emocional. A parede com vegetação para deixar o ambiente o mais natural possível, também com o objetivo de causar serenidade. $\mathrm{O}$ verde e a natureza possuem o poder de tranquilizar as pessoas. Para a qualidade de apresentações e trabalhos, foi projetados o domo e a arquibancada, áreas com formas diferentes, criando ambientes atrativos que despertasse interesse a instigasse a criatividades das crianças.

A escolha do desenho do domo geodésico foi definida através dos estudos de membrana de tração desenvolvidos por Sanchez, Serna e Morer (2018), onde são descritos os processos de dimensionamento das membranas de tração, desde os esboços preliminares até a realização da estrutura.

O projeto foi dividido em uma série de estruturas com possibilidade de ser executadas de forma isolada de modo a viabilizar a execução em etapas. Cada uma das estruturas tem uma função nas atividades educacionais e culturais previstas e abrirá possibilidades para que os professores diversifiquem métodos de ensino de acordo com o programa de necessidades, como: contação de histórias, brincadeiras, teatro, atividades com os pais, atividades abertas à comunidade, eventos, entre outros.

Figura 5 - Projeto arquitetônico da passarela, domo geodésico, lago, arquibancada e parede com vegetação.
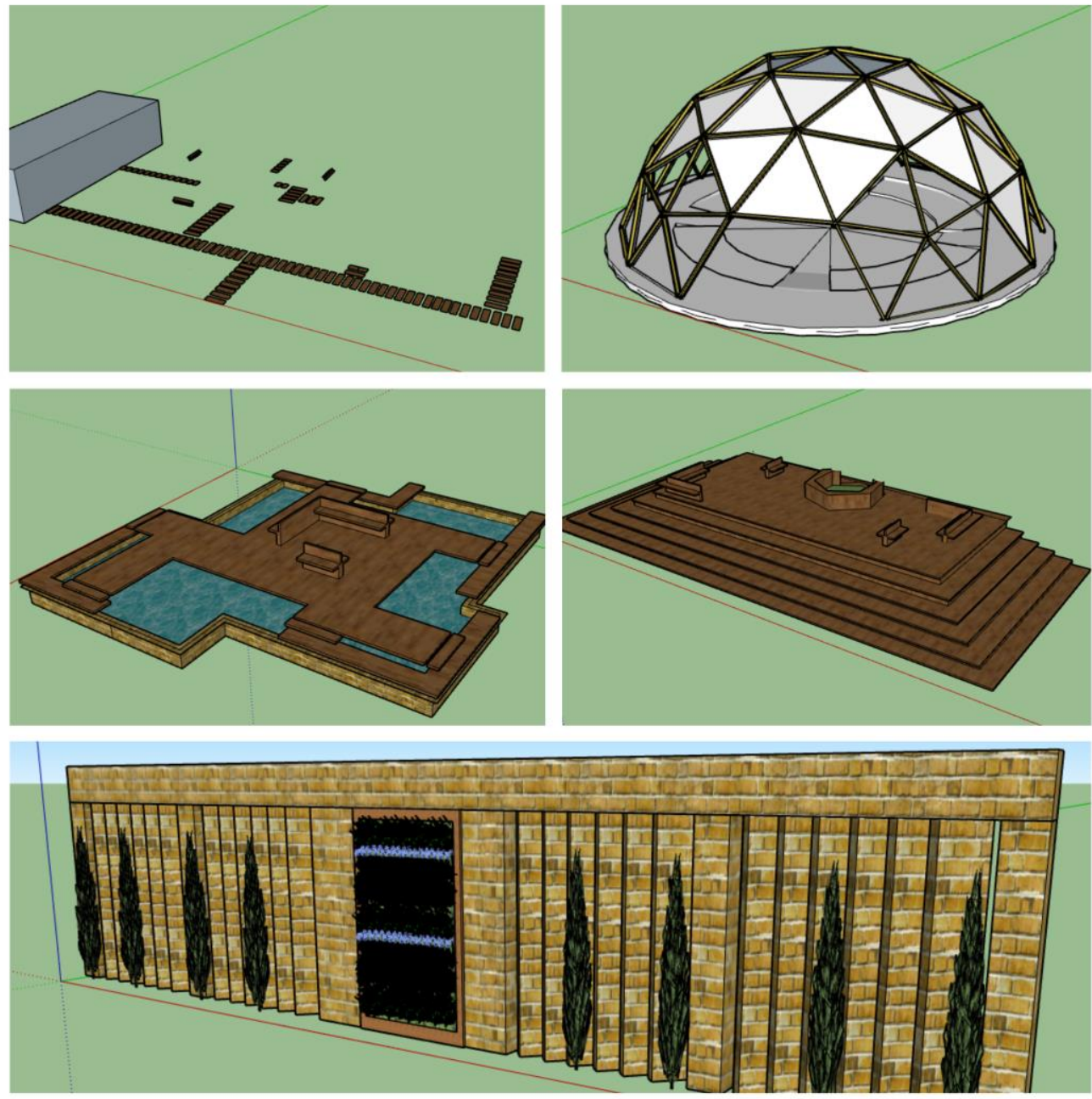

Fonte: Arquivo pessoal. 
Os itens escolhidos na composição foram: a arquibancada/deck sob as árvores, o deck sobre o lago sazonal, o muro de tijolos com paisagismo, o domo geodésico, e, a passarela que conecta todo o conjunto.

$\mathrm{O}$ arquitetônico completo traz todas as ideias que foram pensadas e projetadas para proporcionar um ambiente natural e ao mesmo tempo inovador. Um ambiente que, além de agradável, fosse bonito. Lugares assim geram um maior interesse e despertam em estudantes uma vontade maior de estar ali, na escola. Essa satisfação impacta diretamente na alfabetização e aprendizado dos alunos.

Figura 6 - Projeto arquitetônico de todos os elementos.
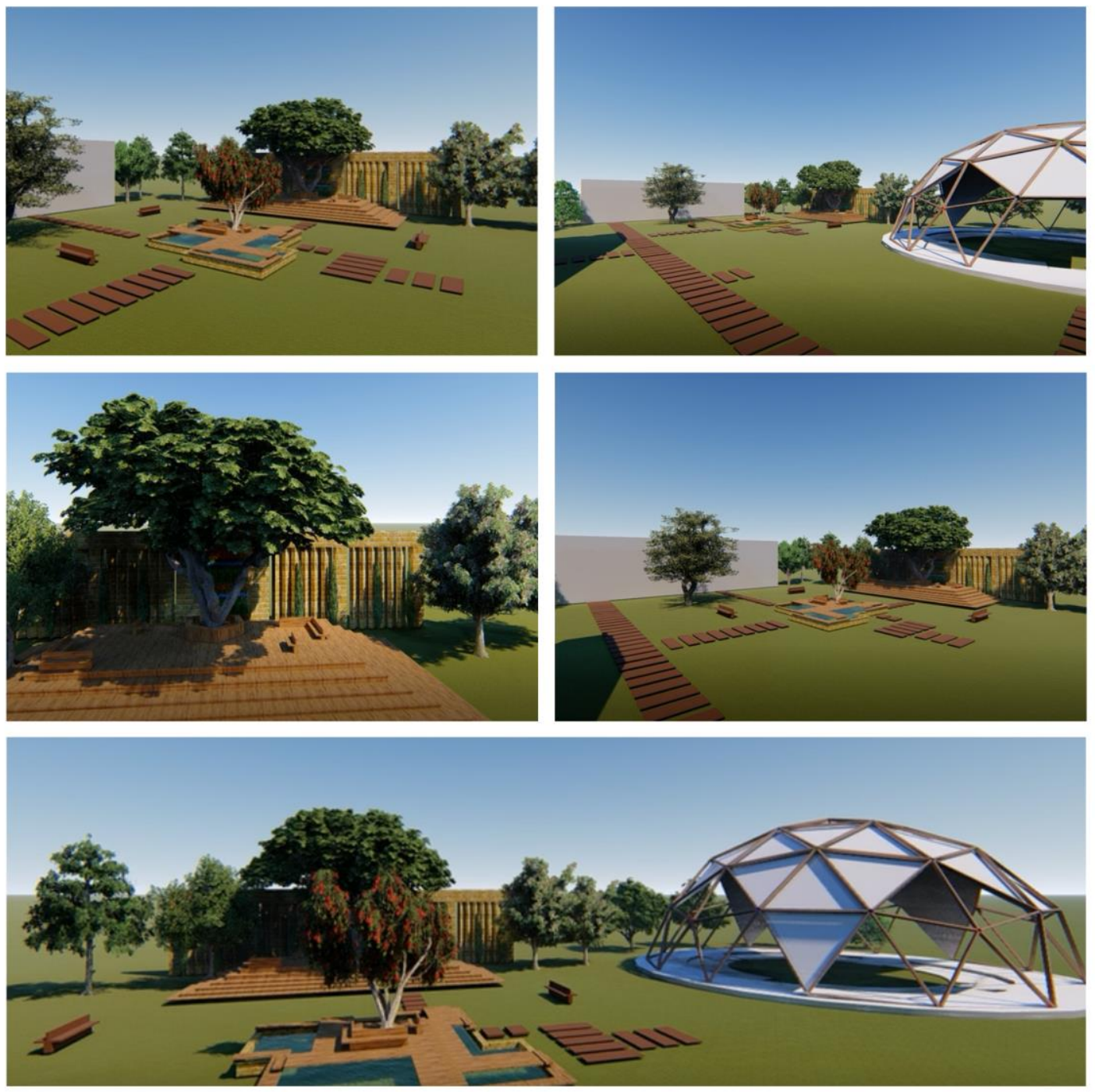

Fonte: Arquivo pessoal.

O anteprojeto arquitetônico foi aprovado em apresentação para a Secretaria de Educação de Curvelo e está em fase de reconhecimento pela comunidade escolar e levantamento de recursos. Pretende-se que o acompanhamento à execução possa ser levado a cabo pelos alunos do CEFET - MG juntamente com os técnicos da Prefeitura de Curvelo. 
Figura 7 - Rascunho da estrutura do lago e da arquibancada.
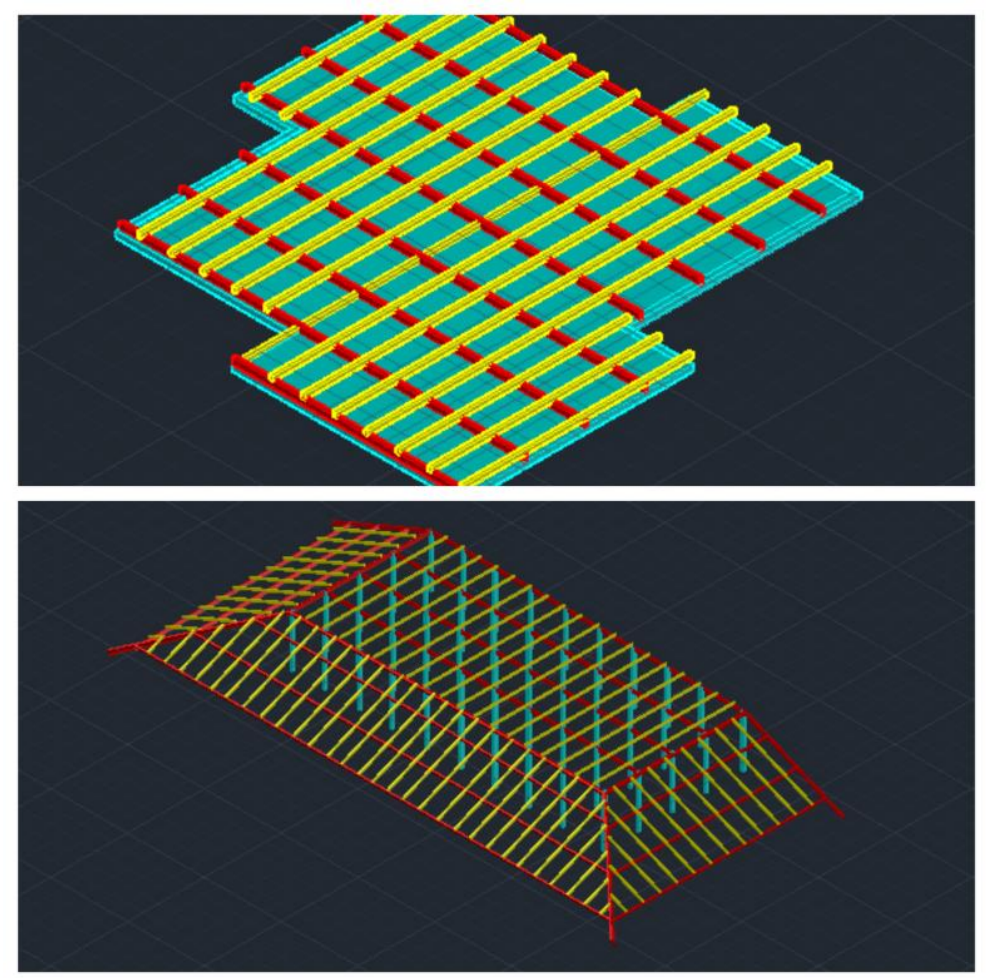

Fonte: Arquivo pessoal.

A partir do projeto arquitetônico, foram elaborados rascunhos dos projetos estruturais da arquibancada e do lago para auxiliar na elaboração do quantitativo de materiais para construção. Nos dois projetos, as vigas, pilares e barrotes serão de madeira e o piso revestido de deck de madeira.

Com o quantitativo de materiais finalizado, a próxima etapa será o orçamento desses materiais e, por fim, a execução das obras.

\section{CONSIDERAÇÕES FINAIS}

Em todas as etapas o projeto Lugar de Ler contribuiu como assistência técnica para o CAIC. Durante o processo de levantamento de documentação e levantamento dos espaços físicos, foi possível ajustar o projeto e preparar as bases para um plano diretor do espaço, que inclui ajustes nos estacionamentos.

Ao pensar em soluções sustentáveis os futuros engenheiros fizeram uso das pesquisas em solo cimento, bambu e madeira de reflorestamento que vem sendo realizadas na unidade CEFET-MG Curvelo. Na geodésica, originalmente proposta em bambu, vem sendo feito o estudo e cálculo das juntas e barras com possibilidade de alteração do material.

A distribuição e ampliação de decks sob as árvores e sobre um lago natural que se forma em períodos chuvosos permitirá que os usuários tenham múltiplos espaços lúdicos para a aplicação de suas metodologias. O paisagismo contará com espécies locais, adaptadas ao clima da região.

Neste projeto de assistência técnica os estudantes de engenharia do CEFET-MG Curvelo tem oportunidade de adquirir novos conhecimentos além de colocar a capacidade técnica 
C COBENCE N2020

"Os desafios para formar hoje o engenheiro do amanhã"

instalada e as especialidades características dos profissionais, ainda em formação, a serviço da comunidade e, além disso, vivenciar aspectos da função social da atividade profissional.

\section{Agradecimentos}

Agradecemos a Diretoria de Extensão e Desenvolvimento Comunitário do Centro Federal de Educação Tecnológica o DEDC-CEFET-MG. As diretoras e pessoal da Escola Municipal Dr. Viriato Mascarenhas Gonzaga CAIC e Centro de Educação Infantil - CAIC. À Secretaria de Educação de Curvelo. À Prefeitura Municipal de Curvelo.

\section{REFERÊNCIAS}

GONÇALVES, J.S. RIBEIRO, H.L.S. AVELINO JR, E.A. FREITAS, D.F. FERREIRA. L.P. Design Paramétrico Aplicado ao Projeto de Estruturas Sustentáveis. Semana de Ciência e Tecnologia do CEFET-MG. 2018.

PCN, Parâmetros Curriculares Nacionais. Secretária de Educação Fundamental. Brasília: MEC/SEF, 1998.

SÁNCHEZ, J \& SERNA, Miguel, MORER, P. Surface Fitting Approach For Tensile Membranes Design.2018. 


\title{
Evento On-line
}

\section{COMMUNITY TECHNICAL ASSISTANCE IN THE TRAINING OF ENGINEERING PROFESSIONALS: READING PLACE PROJECT}

\begin{abstract}
The survey Portraits of Reading in Brazil shows that the country lost almost 90 million readers between 2007 and 2011, most of them children, with the intensification of competition with other media and the loss of quality in reading. In partnership with educators interested in developing spontaneous reading skills, the Lugar de Ler project arose, in which engineering students from CEFET-MG Curvelo help a community school to develop solutions for economic and sustainable spaces that support the practice of teaching methodologies. learning. In this process, students apply their installed technical capacity and the characteristic specialties of professionals in training at the service of the community, and allow their students to experience the social function of professional activity..
\end{abstract}

Keywords: Community Technical Assistance. Reading. Sustainability. 